\section{A Novel Approach to Reembedding Thick Resin Sections for Ultramicrotomy}

Kevin M. Imel ${ }^{1,2}$, Consetta M. Helmick ${ }^{2}$, J. Franklin Bailey ${ }^{2}$ ${ }^{1}$ College of Veterinary Medicine, Washington State Unversity 2Electron Microscopy Center, University of Idaho

In transmission electron microscopy (TEM), it is often desirable to focus our attention on certain cells or structures that are sparsely distributed throughout a large tissue block. One method that is often used is to serially section through a large tissue block and then scan each thin section on the TEM for the cell or structure of interest. A much simpler and far less tedious method is to cut thick sections of the resin block, screen the sections using light microscopy for the cells or structures of interest and then somehow reembed only those sections with the cell or structure of interest so that they can be thin sectioned for TEM. This paper presents a simple and effective approach to this reembedding process that we have employed in our lab for the past three years with excellent results.

Once your sample is embedded in your usual EM resin, proceed to cut thick sections (i.e., $10-15 \mu \mathrm{m}$ ), place them in a small water drop on clean glass microscope slides and dry them using a moderate amount of heat to help flatten the sections and affix them to the glass slide. Be sure to mount the sections far enough apart so that the rest of the procedure can be carried out, mounting no more than two sections per slide, spaced approximately 3 $\mathrm{cm}$ apart is a good rule of thumb.

The thick sections can now be screened using light microscopy for the structures of interest. Those sections containing the structure are marked for later reembedding. Immersion oil can be used directly on the mounted thick sections and is especially helpful in minimizing any chatter lines and knife marks that may be present. This is especially important if the sections are to be later photomicrographed and used in constructing a light to electron microscopic correlation of the same structure of interest. The immersion oil should be removed immediately after screening and reapplied later if necessary as prolonged contact with immersion oil will loosen the sections from the slide making the reembedding procedure difficult. Be sure to use an immersion oil that is soluble in ethanol so that it can be removed before reembedding is performed without damage to the thick section. Since the sections have been heat dried onto the glass slide a fairly vigorous ethanol wash can be used to remove the oil. Large thick sections can also be trimmed using a sharp knife to remove any material that you do not wish to reembed

Before reembedding, rinse the sections in $70 \%$ ethanol to remove any oil and/or debris and allow to air dry. Next, cut off the conical end of a standard sized Beem ${ }^{\mathrm{TM}}$ capsule (or epindorf centrifuge tube of a size that will fit in your microtome chuck) with a sharp knife so that it forms a short (approximately $1 \mathrm{~cm}$ long) plastic barrel. Place the barrel around the thick section and affix to the glass slide using standard 5 minute household epoxy (Figure 1). Use only enough epoxy to seal the barrel onto the glass slide to prevent the casting resin from leaking out, but not so much that it will accidentally flow onto the thick resin section. After the epoxy has set (5 - 10 minutes), fill the barrel with new casting resin of your choice and cure as usual

Once the embedding resin has cured and cooled, the plastic barrel containing the new resin block containing the thick section can be removed from the glass microscope slide by immersing the slide in liquid nitrogen for a few seconds. Many of the resin blocks will dislodge from the glass slide on their own, others may have to be tapped gently before they will fall free. The new resin block can now be punched out of the plastic barrel

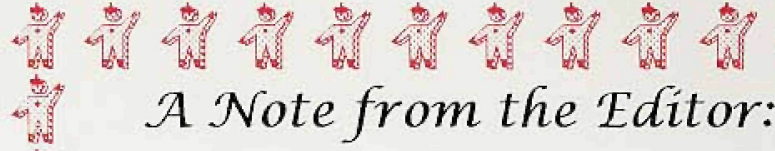

Prior to starting this pubfication, I happen to have been involved in the "electron" version of microscopy. It was therefore natural that the initial content of the publication was heavily reslated to electron microscopy. Today, that emphasis does tend to continue.

A number of readers have commented that they would like to see more emphasis on other microscopy techniques. This is clearly my intent - not by reducing electron microscopy content, but by increasing publication size, which is possible due to increased advertising income.

To meet the objective, however, I need your help. The production of each issue is difficult - due only to the lack of articles and material of real value and interest to our readers.

Contributions do not have to be long. In fact, I particularly appreciate shorter articles. The only criteria is that the subject be of interest to a reasonable number of working microscopists. Images, iltustrations, etc, even in color, are welcome.

And, while I am asking for your help. I hope that you widl route this issue to others of your acquaintance with an interest in microscopy. We would be delghted to add them to our mailing list.

Lastly, should you enjoy the publication, you might express your thanks to our advertisers - who make this pubication possible.

Thank you for your consideration. -.. Don Grimes, Editor

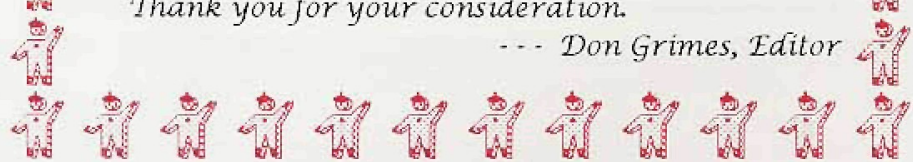

Warning! Some blocks may still have small flakes of glass stuck to the surface which will damage your diamond knife. These glass flakes can be easily removed by carefully prying with a sharp razor blade or scribe or by repeated immersion of the block in liquid nitrogen. Be sure and take precautions against flying debris when you do this!

The new resin block (Figure 2) can now be trimmed and faced for ultramicrotomy in the usual fashion. Remember, the section of tissue that is available to cut is only as thick as your original thick section. Careful trimming and facing combined with careful alignment in the ultramicrotome will usually yield many thin sections.

By following this simple procedure, unique structures and cells can be identified quickly and with less frustration than screening grid after grid of sections. It also allows for easy light and electron microscopic correlation of the same cell or structure without many of the problems associated with using adjacent serial sections 


\section{MORE HUMORP??}

\section{Electricity 101: The Real Story}

What is electricity, really? And where does it go after it leaves the toaster?

Here is a simple experiment that will teach you an important electrical lesson. On a cool, dry day, scuff your feet along a carpet, then reach your hand into a friend's mouth and touch one of his dental fillings. Did you notice how your friend twitched violently? Did you get bit? This teaches us that electricity can be a very powerful force, and we must never use it to hurt others unless we need to learn an important electrical lesson.

It also teaches us how an electrical circuit works. When you scuff your feet, you picked up batches of "electrons," which are very small objects that carpet manufacturers weave into carpet fibers so they will attract dirt. The electrons travel through your blood stream and collect in your finger, where they form a spark that leaps to your friend's filling, then travels down to his feet and back into the carpet, thus completing the circuit

Amazing Electronic Fact: If you scuff your feet long enough without touching anything, you can build up so many electrons that your finger would explode! But this is nothing to worry about unless you have carpeting.

Although we tend to take our electrical appliances for granted, a hundred years ago people did not have such things, which is just as well because there was no place to plug them in. Then along came electrical pioneer Benjamin Franklin, who flew a kite in a lightning storm and received a serious electrical shock, thus proving that lightning was powered by the same force as carpets. Unfortunately, the experiment so damaged

\section{Electron Fliglt Simulator 2.0}

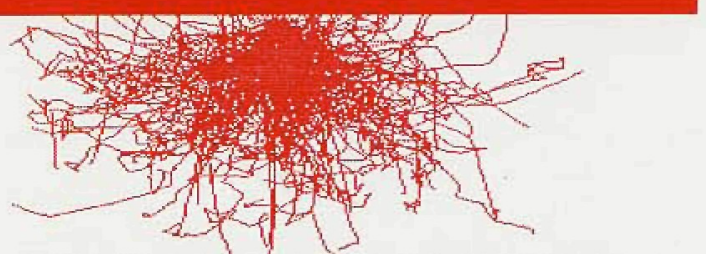

Electron Flight Simulator, software for Windows, lets you model your sample and electron microscope conditions so you can see where your $\mathrm{x}$-ray signal is coming from. Have more confidence in your analysis with less guesswork. $\mathrm{X}$-ray analysis will never be the same.

- Model a Bulk, Thin Film, or Film on a Substrate - Model up to Five Layers, Alone or on a Substrate

- Model any Sample Chemistry at any Accelerating Voltage

- Model Particles on a Sample or Inclusions in a Sample

- Model Vertical Interfaces Between Layers

- Model any Sample Tilt from 0 to 90 Degrees

- Display PhiRhoZ Depth of X-ray Generation Plots

- Display X-ray and Electron Interaction Volumes

- Display Electrons by Color Change at Each 10\% Energy Loss

- Print Your Models or Save Them as Image Files

- On-Line Help Menus

- On-Line Periodic Table and Chemistry Calculator TM

- Unlimited Free Technical Support

- The Perfect Teaching and Training Tool

\section{Small World}

P.O. Box 25284 San Mateo, CA 94402

Phone/Fax (415) 345-8013

e-mail: DCHERNOFF@AOL.COM
Franklin's brain that he had to be given a job running the Post Office.

Following Franklin came a herd of electrical pioneers whose names have become part of our electrical terminology: Myron Volt, Mary Louise Amp, James Watt, Chuck Transformer, and so on. In 1780, Luigi Galvani discovered that when he attached electrodes to the leg of a frog, the frog's let kicked, even though it was no longer attached to the frog. Galvani's discovery led to enormous advances in the field of amphibian medicine. Today, a skilled veterinarian can take a dead frog and make it hop back into the pond just like a live frog, except that it stinks.

But the greatest electrical inventor of them all was Thomas Edison. Edison's greatest achievement came in 1879 when he invented the Electric Company. His design was a brilliant adaptation of the simple electrical circuit. The electric company sends electricity through a wire to a customer, then immediately gets the electricity back thorough another wire. then (this is the brilliant part) sends it right back to the customer again.

This means that an electric company can sell a customer the same batch of electricity thousands of times a day and never get caught, since very few customers take the time to examine their electricity closely. No new electricity has been generated in the United States since 1937. The electric companies have been merely reselling it ever since, which is why they have so much time to apply for rate increases to pay for excessive wear and tear on their carpeting.

Today, thanks to men like Edison and Franklin, and frogs like Galvani's, we receive unlimited benefits. For example, scientists have perfected the laser, an electronic device so powerful that it can vaporize a bulldozer, yet so precise that doctors can use it to perform delicate operations on the human eyeball - provided that they remember to change the power setting from "Vaporize Bulldozer" to "Delicate Eye Surgery."

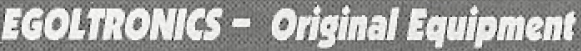

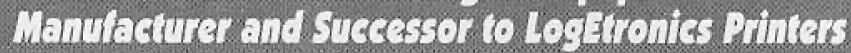

\section{EM 55 Enlarger Offers Latest MultiDodge Technology To Reveal Detail Previously Unavailable}

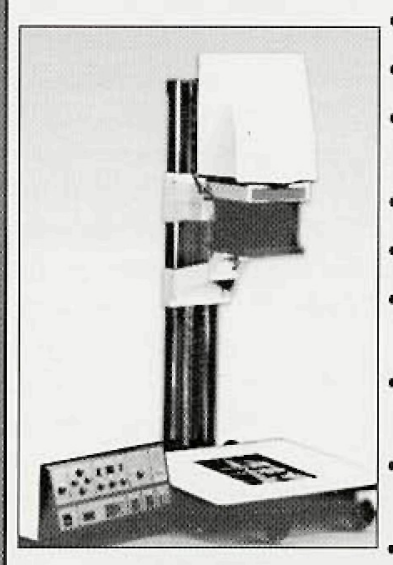

Prescan

- Microprocessor Control

Modular Electronies, Built in Diagnostics

- 64 Exposure Programs

- Menu Driven, Data Displayed

- Smaller Spot Size - Variable to $0.02^{\prime \prime}$

\section{- Intensity AND Velocity Modulation}

- Individual Highlight and Shadow Dodging

Four Brightness Levels

\section{Special Offer From Egoltronics}

- Send your negatives with a description of what you are looking for, and we will return your negatives with prints showing what you specified.

- If you would like to receive our Electronic Image Enhancement Newsletter and other timely information, call our offices at 703-335-1501 or fax your name and address to 703-335-1234.

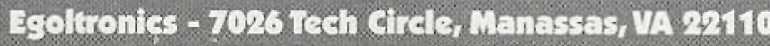

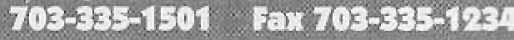


$\checkmark$ August 6/11 95: Microbeam Analysis Society (MAS) National Meeting. Breckenridge, CO. Gregory Meeker, Tel: (303)236-1081, Fax: (303)236-1414.

$\checkmark$ August 6/11'95: XIVth International Pfefferkorn Conference on the Science of Biological Specimen Preparation for Microscopy and Microanalysis. Belleville, IL. Marek Malecki: (608)263-8481, Fax: (608)233-2400.

$\checkmark$ August 13/17 '95: Microscopy Society of America/Histochemical Society Annual Meeting. Kansas City, MO. (800)538-3672 or (508)540-5594, Fax: (508)548-9053,

mmaser@mbl.edu

$\checkmark$ August 29/Sept 2 '95: 14th International Congress on X-ray Optics \& Microanalysis. GuangZhou, China. Tel:: 8620-777-5213, Fax: 8620-777-5791.

$\checkmark$ Sept '95: 1st International Conference of Electron Microscopy and Advances in Research in Different Fields of Science. Ismailia Egypt. Dr. Khalifa Ibrahim Khalifa: Phone/fax: (20)64-329478.

$\checkmark$ Sept 2/6 '95: 3rd Interamerican Congress of Electron Microscopy. Caxambú MG, Brazil. Elliot Kitajima, Tel.: 55-61-348-2424, Fax: 55-61349-9094, kitajima@guarany.cpd.unb.br

$\checkmark$ Sept 4/8 '95: New Zealand Microscopy Conference '95. (NZSEM). Dunedin, New Zealand. Allan Mitchell, 6434797301 , Fax: 64 34797254 , allan.mitchell@stonebow.otago.ac.nz $\checkmark$ Sept 8 '95: High-Resolution Fluorescence Microscopy Seminar. (Scanalytics \& Universal Imaging Corp) Boston, MA. Sue Ellis: (800)8826247, Fax: (508)663-0150, scan-info@cspi.com

$\checkmark$ Sept 12/15 '95: EMAG 95. Univ of Birmingham, UK, 44-171-235-6111, Fax: 44-171-823-

1051, iopconf@ulcc.ac.uk

$\checkmark$ Sept $20^{\prime} 95$ : Chicago, IL

Sept 27 '95: Newark, NJ

Short Course on Image Analysis (Imanalco 95). John Keith Beddow: Tel/Fax (319) $337-2474$

$\checkmark$ Sept 26/Oct 2 95: 14th International EM Congress. Cancun, Mexico. Miguel Jose Yacaman: 525-570-85-03 Fax: 525-570-85-03

$\checkmark$ Sept 26/30 95: OlM Academy-EBSP \& Orientation Imaging Microscopy. (TSL, Inc.). Provo, Utah. David Dingley: Tel: (801)344-8990, Fax: (801)344-8997.

$\checkmark$ Sept 29/Oct 1 '95: Symposium on Integrated Microscopy. (Integrated Microscopy Resource, U of WI). Madison, WI. IMR, Univ. of WI, 1675 Observatory Drive, Madison, WI 53706. imradmin@calshp.cals.wisc.edu

$\checkmark$ Sept 29/0ct 1 95: 14th Annual Advances in Microscopy Symposium "Microscopy Outreach: Conveying its Science, Art \& Technol- ogy" (NCSMMA). Wrightsville, NC. Peter Ingram: (919)541-6598, Fax: (919)681-8419, ingram@rti.org

$\checkmark$ Sept 29/0ct 1 "95: First Annual Symposium on Integrated Microscopy. Univ. of Wisconsin, Madison. imradmin@calshp.cals.wisc. edu

$\checkmark$ Oct 4/5 95: International Seminar on Quantitative Microscopy. Braunschweig, Germany. H. Geuther: Fax: 495315924015 , heinrich.geuther @ptb.de

$\checkmark$ Oct 5 '95: CCD Imaging Workshop (Photometrics) Tucson, AZ. Lisa Soroka: (520)889-9933, Fax: (520)295-0299.

$\checkmark$ Oct 9/13 95: Scanning Electron Microscopy and X-Ray Microanalysis for the Materials Scientist. (SUNY - Inst. of Materials Science). New Palt, NY. Dr. A.V. Patsis: Tel.: (914)257-3800, Fax: (914)255-0978.

$\checkmark$ Oct 12/14 '95: Great Lakes Microscopy Conference ' 95 . (GLeMA) Toledo, $\mathrm{OH}$. Dr. Carol Heckman: (419)372-8218 $\checkmark$ Oct 16/20'95: AVS Annual National Symposium. Minneapolis, MN. Tel. (212)248-0200, Fax: (212)248-0245.

$\checkmark$ Oct 17/20'95: Scanning Electron Microscopy and X-Ray Microanalysis for the Material Scientists. (SUNY) New Paltz, NY (914)255-0757, Fax: (914)255-0978

$\checkmark$ Oct 24/27 '95: Ultramicrotomy in Materials Science (RMC and Univ. of Arizona). Tucson, AZ. Bob Chiovetti: (520)889-7900, Fax: (520)741-2200.

$\checkmark$ Nov 15 '95: 23rd Scottish Microscopy Symposium. Edinburgh, Scottland. Stephan Helfer: 0131 552-7171, Fax: 0131 552-0382, Stephan@rbge.org.uk

$\checkmark$ Nov 28/Dec 1 '95: 34th Annual Conference of the Electron Microscopy Society of Southern Africa (EMSSA '95). Prof. Mike Lee, EM Unit, Univ. of the North, Private Bag X1106, Sovenga 0727, South Africa. email: qemssa95@uninl.north.ac.za

$\checkmark$ 5/9 Feb 96: 14th Australian Conference on Electron Microscopy (ACEM-14) \& 1st Meeting of the International Union of Microbream Analysis Societies (IUMAS). Sydney, Australia. Maret Vesk: 61-2-351. 2351, Fax: 61-2-552-1967

$\checkmark$ July 2/4 '95: MICRO '96 (RMS), London, U.K. 441865248768 , Fax: 441865791237

$\checkmark$ 14/19 July '96: 43rd International Field Emission Symposium.

$\checkmark$ Aug 96: 6th Asia-Pacific Conference on Electron Microscopy, APEM 6 . Hong Kong. Dr. E.C. Chew: 852609 6845, Fax: 852 6035031
Electron Microscopy...

\section{...through quality, innovation \& customer support.}

Carl Zeiss offers a full range of pace-setting products, featuring the latest innovations in electron optics.

- New EM 906 - continuous zoom TEM with stable image orientation from 40 to $600,000 \mathrm{X}$

- EM 912 OMEGA - only TEM with leading edge OMEGA electron energy spectrometer.

- EM 910 - versatile TEM providing advanced Koehler illumination.

- New DSM 982 GEMINI - field emission SEM with patented lens, optimized detector position, superb resolution \& imaging at low kV.

- DSM 962- research SEM featuring high-resolution image storage \& processing.

- DSM 940A - fully digital, economical SEM with exceptional features \& value.

(800) 356-1090

Fax (914) $681-7443$

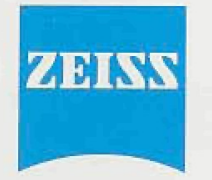

Carl Zeiss, Inc.

Electron Optics Division One Zeiss Drive Thornwood, NY 10594

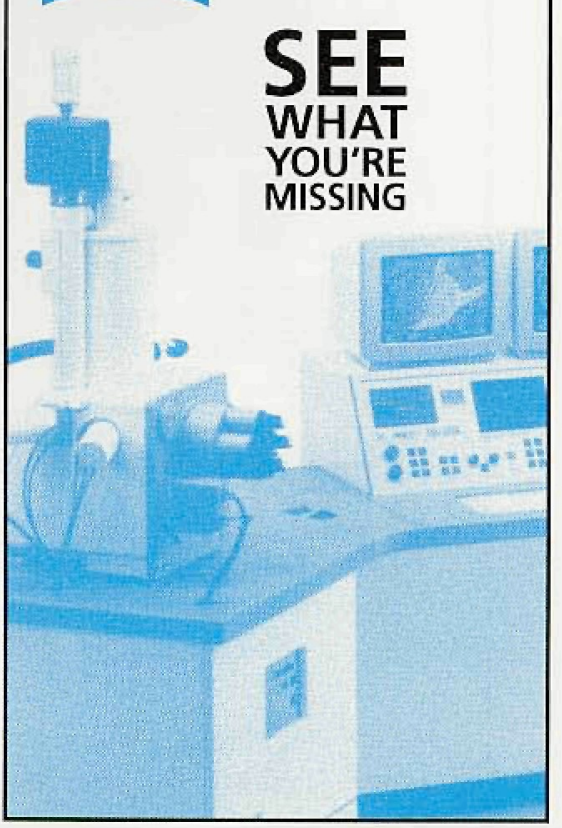

